\title{
Avaliação de culturas microbianas para a elaboração de kombucha
}

\author{
Evaluation of microbial cultures for the preparation of kombucha \\ Evaluación de culturas microbianas para la preparación de kombucha
}

Recebido: 27/10/2021 | Revisado: 06/11/2021 |Aceito: 26/11/2021 | Publicado: 07/12/2021

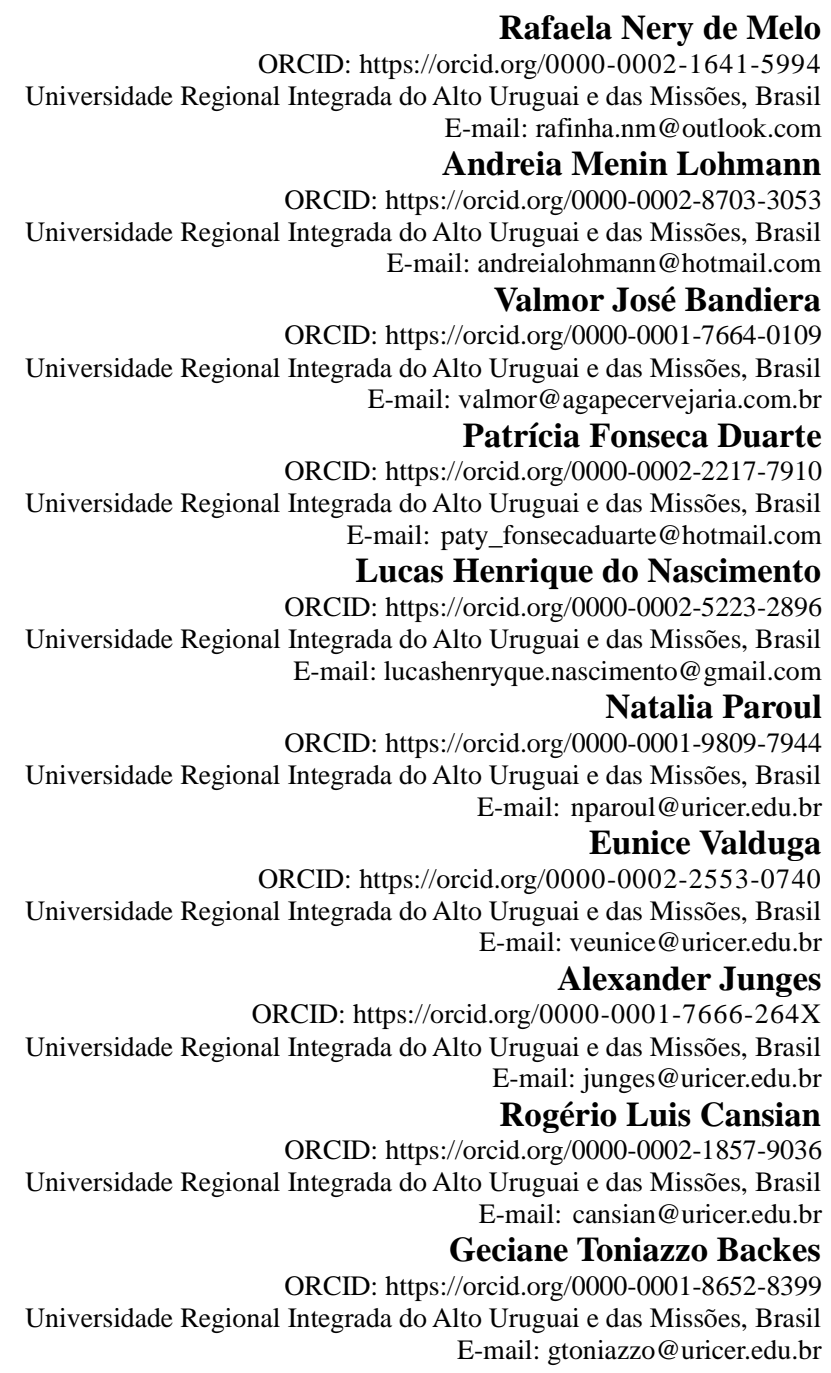

\section{Resumo}

A Kombucha é uma bebida obtida pela fermentação de chá verde e/ou preto adicionada de uma fonte de açúcar, submetida a uma fermentação simbiótica entre leveduras e bactérias presentes nos botânicos agregados ou de cultura previamente selecionada e ou armazenada. A crescente popularidade da kombucha deve-se as propriedades antioxidantes, vitaminas do complexo B e ácidos orgânicos, comprovadamente benéficos à saúde. Neste trabalho foram produzidas formulações de Kombucha com 3 diferentes culturas de microrganismos. O extrato do chá foi preparado com ervas e especiarias encontradas no mercado local e a fonte de açúcar foi o mel. As formulações foram submetidas a fermentação durante 11 dias. Foram realizadas análises físico-químicas, antes e após a fermentação. Após a fermentação a bebida foi carbonatada e dividida em dois grupos, pasteurizada e in natura. Passados 8 dias as amostras foram submetidas a uma análise sensorial. Os resultados com levedura industrial e da mãe do vinagre, leveduras nativas e da mãe do vinagre e cultura mista de bactéria e levedura (cultura mãe do vinagre) proporcionaram sabores e aromas distintos, sendo que o tratamento com levedura indústrial + nativa tiveram taxas de metabolização dos açucares maiores com consequente maior formação de álcool e redução de açúcares, porém menor formação de ácidos. Na avaliação sensorial a cultura mãe obteve maior aceitação. O tratamento térmico prejudicou sensorialmente as formulações. A cultura mãe isolada obteve as melhores pontuações quando in natura. 
Palavras-chave: Kombucha; Cultura microbiana; Fermentação.

\begin{abstract}
Kombucha is a drink obtained by the fermentation of green and/or black tea added to a source of sugar, subjected to a symbiotic fermentation between yeasts and bacteria present in aggregated botanicals or from previously selected and/or stored culture. The growing popularity of kombucha is due to its antioxidant properties, B vitamins and organic acids, which have been shown to be beneficial to health. In this work Kombucha formulations were produced with 3 different cultures of microorganisms. The tea extract was prepared with herbs and spices found in the local market and the source of sugar was honey. The formulations were submitted to fermentation for 11 days. Physicochemical analyzes were performed, before and after fermentation. After fermentation, the drink was carbonated and divided into two groups, pasteurized and in natura. After 8 days the samples were submitted to a sensory analysis. The results with industrial yeast and vinegar mother, native yeast and vinegar mother and mixed culture of bacteria and yeast (vinegar mother culture) provided distinct flavors and aromas, and the treatment with industrial + native yeast had metabolization rates of higher sugars with consequent greater formation of alcohol and reduction of sugars, but less formation of acids. In the sensory evaluation, the mother culture was more accepted. The thermal treatment affected the formulations sensorially. The isolated mother culture obtained the best scores when in natura.
\end{abstract}

Keywords: Kombucha tea; Microbial culture; Fermentation.

\title{
Resumen
}

La kombucha es una bebida obtenida por fermentación de té verde y/o negro agregado a una fuente de azúcar, sometido a una fermentación simbiótica entre levaduras y bacterias presentes en botánicos agregados o de cultivo previamente seleccionado y/o almacenado. La creciente popularidad de la kombucha se debe a sus propiedades antioxidantes, vitaminas B y ácidos orgánicos, que han demostrado ser beneficiosos para la salud. En este trabajo se produjeron formulaciones de Kombucha con 3 cultivos diferentes de microorganismos. El extracto de té se preparó con hierbas y especias que se encuentran en el mercado local y la fuente de azúcar fue la miel. Las formulaciones se sometieron a fermentación durante 11 días. Se realizaron análisis fisicoquímicos, antes y después de la fermentación. Después de la fermentación, la bebida se carbonató y se dividió en dos grupos, pasteurizada e in natura. Después de 8 días, las muestras se sometieron a un análisis sensorial. Los resultados con levadura madre industrial y vinagre, levadura madre nativa y vinagre y cultivo mixto de bacterias y levadura (cultivo madre vinagre) proporcionaron sabores y aromas distintos, y el tratamiento con levadura industrial + nativa tuvo tasas de metabolización de azúcares superiores con la consecuente mayor formación de alcohol y reducción de azúcares, pero menor formación de ácidos. En la evaluación sensorial, la cultura madre fue más aceptada. El tratamiento térmico afectó sensorialmente las formulaciones. La cultura madre aislada obtuvo las mejores puntuaciones cuando estaba in natura.

Palabras clave: Kombucha; Cultivo microbiano; Fermentación.

\section{Introdução}

Tem se observado crescente preocupação em relação à origem dos alimentos, além do impacto destes ao meio ambiente e a saúde, estimulando as pessoas a repensarem suas fontes de consumo (Hill et al., 2017; Schmitt et al., 2017; Selhub et al., 2014). Nesse contexto, foi observado um aumento na procura de produtos feitos em casa e/ou provenientes de pequenos produtores locais, conhecidos como produtos artesanais (Kaur \& Singh, 2017). Esse interesse, principalmente em relação a alimentos funcionais, aumentou a importância dos fermentados tradicionais, como o chá de kombucha e o kefir conhecidos por seus benefícios à saúde (Sarkava et al., 2020).

Kombucha é uma bebida funcional originária da Ásia, que vem se popularizando também como alternativa aos refrigerantes já que é levemente ácida e carbonatada (Jayabalan et al., 2010). As propriedades funcionais do chá de kombucha, como suas atividades antioxidantes e antimicrobiana são atribuídas aos seus polifenóis (epicatequina, epicatequina-3-galato, epigalocatequina e epigalocatequina-3-galato), ácido glucônico, ácido glucurônico, ácido lático, vitaminas, aminoácidos, antibióticos e uma combinação de micronutrientes produzidos durante a fermentação. Trata-se de uma bebida probiótica com significativa ação principalmente na saúde intestinal (Vijayaraghavan et al., 2000; Battikh et al., 2012; Dufresne \& Farnworth, 2000; Malbasa et al, 2008; Nguyen et al., 2015).

Consiste, usualmente, no preparo do chá verde ou preto adocicado, fermentado através da adição de uma cultura simbiótica de leveduras e bactérias (SCOBY - Symbiotic Culture of Bacteria and Yeasts), acomodadas em uma matriz de celulose. Pode ainda ser realizada uma segunda fermentação para carbonatar a kombucha, adicionando-se uma nova fonte de 
açúcar à bebida (Santos, 2016). A composição do kombucha pode variar de produção a produção, dependendo do tipo de SCOBY inoculado, do chá utilizado, do tempo e, também, da temperatura de fermentação (Jayabalan et al, 2014).

O SCOBY geralmente compõe-se de bactérias (Acetobacter xylinum, Acetobacter xylinoides e Bacterium gluconicum) e leveduras (Schizosaccharomyces pompe, Saccharomyces ludwigii, Zygosaccharomyces rouxii, Candida spp. e Pichia spp.) que são cultivadas em açúcar tradicionalmente do chá, mas também de outras matérias-primas, normalmente vegetais (cereais ou folhas de plantas) ou produtos animais (por exemplo, leite) e até cogumelos (Gamboa-Gomez et al., 2017; Lobo, Sagar, e Shenoy, 2017; Malbasa et al., 2014; Sknepnek et al., 2018; Vitas et al., 2013).

As bactérias são responsáveis pela produção de um biofilme superficial que forma a chamada "mãe da kombucha" (Dufresne, Farnworth, 2000). Já as leveduras são responsáveis pela hidrólise da sacarose da base do chá em frutose e glucose pela ação da enzima invertase, e produzem etanol e dióxido de carbono, sendo que algumas delas tem preferência por glicose, e outras têm preferência por frutose como substrato (Jayabalan et al., 2014).

A duração do processo de fermentação pode afetar não apenas as características sensoriais do produto, mas também a estabilidade e, portanto, as atividades biológicas de seus componentes (Amarasinghe et al, 2018; Jayabalan et al., 2008).

Em relação à composição química das bebidas de kombucha, ela também muda de acordo com os fatores mencionados e a diversidade microbiana. No entanto, uma composição geral para kombucha pode ser composta por ácidos orgânicos (como resultado da atividade microbiana, por exemplo, ácidos acético, lático, glucônico, glucurônico e oxálico), açúcares (incluindo uma pequena quantidade de sacarose não hidrolisada, mas principalmente glicose e frutose), proteínas, etanol, polifenóis (diferentes espécies moleculares dependendo da matéria-prima utilizada), vitaminas $\left(\mathrm{B}_{1}, \mathrm{~B}_{6}, \mathrm{~B}_{12}, \mathrm{C}\right)$, minerais $(\mathrm{Cu}, \mathrm{Fe}, \mathrm{Mn}, \mathrm{Ni}, \mathrm{Zn})$, ânions $\left(\mathrm{F}^{-}, \mathrm{Cl}^{-}, \mathrm{Br}^{-}, \mathrm{I}^{-}, \mathrm{NO}^{3-}, \mathrm{HPO}^{4-}, \mathrm{SO}^{4-}\right)$ e compostos bioativos específicos, como ácido Dsacárico-1,4-lactona (DSL) (Roos e Vuyst, 2018; Greenwalt et al, 2000; Jayabalan et al., 2014; Villarreal-Soto et al., 2018; Watawana et al., 2015). Em termos de compostos fenólicos, os grupos mais abundantes são os flavonóides e os ácidos fenólicos disponíveis em todas as variedades de Kombucha (Cardoso et al., 2020). As catequinas como um subgrupo de polifenóis, principal grupo de flavonóides e estão presentes nas folhas de chá verde, aumentam as propriedades antioxidantes, incluindo a atividade de eliminação de radicais livres (Jayabalan et al, 2007; Srihari \& Satyanarayana, 2012). Kombucha contém ácidos orgânicos, como ácido glucurônico, ácido acético são outros compostos importantes (Cardoso et al., 2020).

Visando o desenvolvimento de chá de Kombucha em condições regionais, o presente trabalho teve como o objetivo selecionar cepas de leveduras para preparar bebidas tipo Kombucha, além de avaliar diferentes formulações.

\section{Metodologia}

O presente trabalho consiste de um estudo experimental, com o uso de metodologias quantitativas e qualitativas (Köche, 2011; Pereira et al., 2018) as quais são descritas a seguir.

\subsection{Isolamento da Cultura Mãe}

A cultura mãe (Figura 1) foi cedida gentilmente pelo laboratório BIO4 Soluções Tecnológicas da Fazenda Rio Grande-PR. Esta cultura é iniciada a partir de vinagre colonial e adicionada de fermentados de caqui e maçã. 
Figura 1. Aspecto macroscópico da Cultura Mãe.

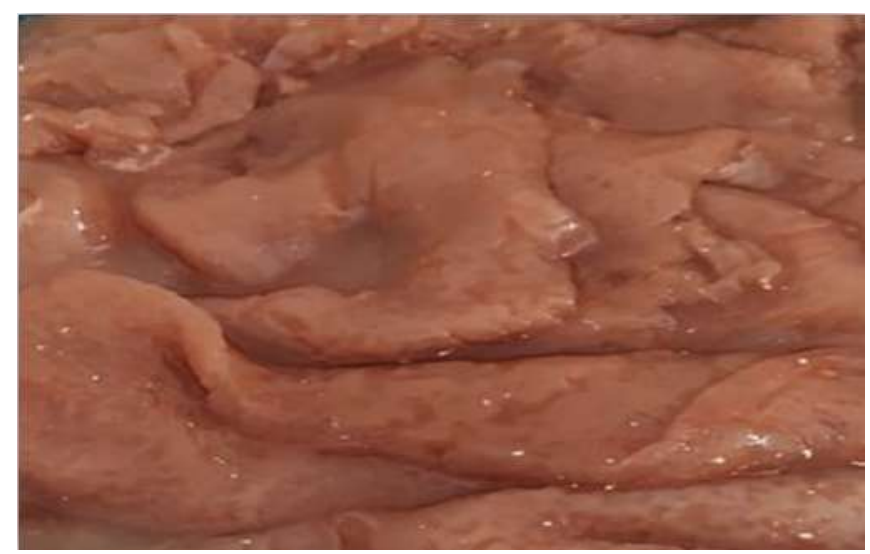

Fonte: Autores.

\subsection{Seleção de leveduras para fermento nativo}

Para a seleção de leveduras fermentativas, realizou-se a preparação de um mosto a base de frutas nêspera, laranja, lima e jabuticaba. A metodologia utilizada foi cedida pelo laboratório BIO4 soluções biotecnológicas, onde, primeiramente misturou-se $8 \mathrm{~g}$ de extrato de malte, $8 \mathrm{~g}$ de peptona e $4 \mathrm{~g}$ de extrato de levedura. Em seguida, adicionou-se $600 \mathrm{~mL}$ de água destilada e após solubilizar os reagentes sob agitação magnética transferiu-os para um frasco Scott (contendo 7,2 g de ágar em caso de meio sólido). Para finalizar, o material foi esterilizado em autoclave por $121{ }^{\circ} \mathrm{C}$ por $15 \min$.

Para obtenção das culturas mistas utilizou-se 1,4 g/L do meio YPM, 0,044 g/L de verde bromocresol, $1000 \mathrm{mg}$ de antibiótico (para inibir o crescimento de bactérias) e $1000 \mathrm{~mL}$ de água destilada, esterilização a $121{ }^{\circ} \mathrm{C}$ por $15 \mathrm{~min}$ e posteriormente vertidos em placas de petri. Em seguida, as leveduras foram espalhadas nas placas e incubadas a $21^{\circ} \mathrm{C}$ por 3 a 5 dias (Figura 2).

Figura 2. Culturas mistas de leveduras obtidas.

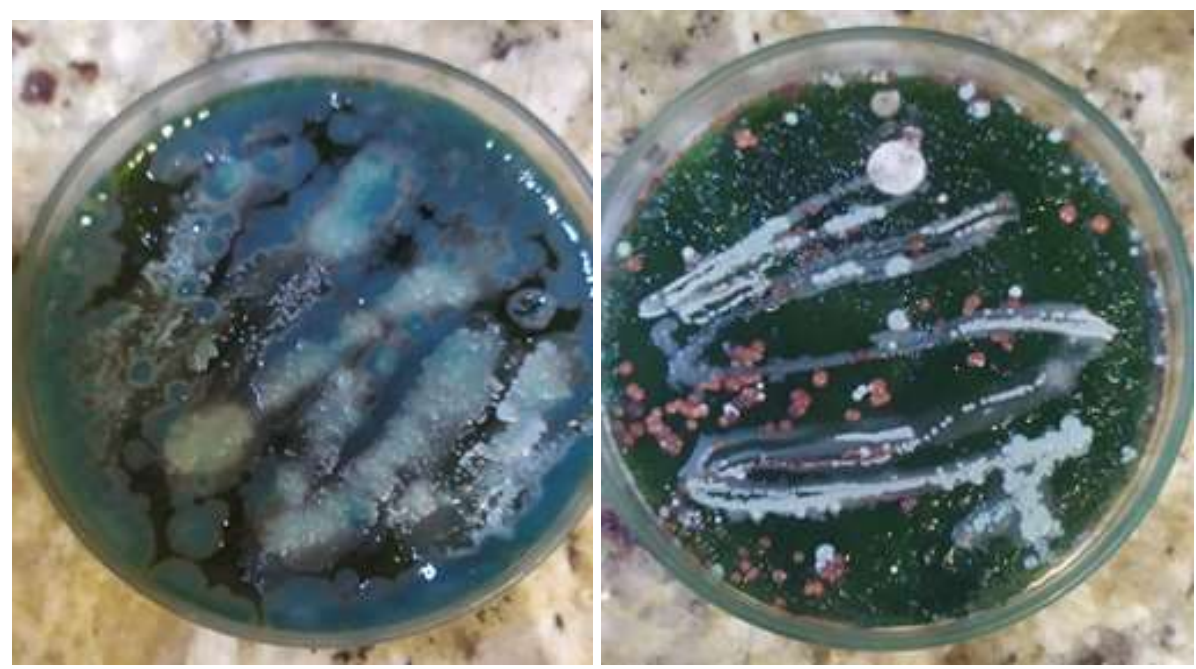

Fonte: Autores.

Foram inoculadas 22 placas, destas selecionou-se as que apresentaram produção de aromas agradáveis e frutados. A seleção dos aromas foi realizada através de análise sensorial. Realizaram-se fermentações prévias, sendo que as que obtiveram melhores resultados foram utilizadas para o posterior inóculo no preparo da Kombucha. Preparou-se 1 L desta cultura (fermento nativo) $\mathrm{O}$ processo de fermentação ocorreu durante 10 dias, servindo de inóculo para a produção de Kombucha. 


\subsection{Preparo da Kombucha}

Para o preparo do chá para a Kombucha, pesou-se $100 \mathrm{~g}$ de chá verde, $100 \mathrm{~g}$ de chá tostado de erva mate, $20 \mathrm{~g}$ de canela em pau, $120 \mathrm{~g}$ de gengibre em pó, $20 \mathrm{~g}$ de cúrcuma em pó, $60 \mathrm{~g}$ de maca peruana em pó, $60 \mathrm{~g}$ de ginsseng em pó, $20 \mathrm{~g}$ de nós de cola, $40 \mathrm{~g}$ de extrato de guaraná e $1 \mathrm{Kg}$ de mel. Todos os ingredientes foram adicionados em $20 \mathrm{~L}$ de água.

A extração para obtenção do chá foi realizada com a água até $85^{\circ} \mathrm{C}$, de chá verde, chá tostado de erva mate e gengibre. Cúrcuma, maçã peruana, gisseng, nós de cola, extrato de guaraná, canela, e mel e o restante dos ingredientes foram adicionados e ficaram em infusão por 5 min. Posteriormente, o chá obtido foi filtrado e deixado esfriar em temperatura de aproximadamente $18^{\circ} \mathrm{C}$. Após resfriar, o chá foi separado em três recipientes com $6 \mathrm{~L}$ cada.

Para a elaboração da kombucha, avaliou-se três combinações de microrganismos distintas: Formulação 1 (F1) Sacharomyces cerevisiae (300 mL) e cultura mãe (600 g); Formulação 2 (F2) - fermento nativo (1 L) e a cultura mãe (600 g); Formulação 3 (F3) - apenas a cultura mãe (600 g). O tempo de fermentação foi de onze dias, permanecendo mais oito dias decantando. Por fim, foram envazadas e carbonatadas e parte das amostras foram pasteurizadas.

\subsection{Caracterização da Kombucha}

Para a caracterização da kombucha, foram realizadas as seguintes análises físico-químicas no início da fermentação, após 24 horas e ao final (11 dias): pH, densidade, teor de sólidos solúveis (Brix), açúcares redutores e acidez total. Sendo realizado no final do processo de fermentação a análise de teor alcoólico.

$\mathrm{O}$ pH foi determinado por método potenciométrico conforme IAL (2009) através da leitura direta das amostras em pHmetro. A densidade foi determinada através do método do picnômetro. Os valores de concentração de açúcares totais dissolvidos foram acompanhados por meio de uso de refratômetro, calibrado com água destilada, para a verificação do Brix da bebida durante seu processo fermentativo.

Realizou-se também testes sensoriais, onde estes foram conduzidos em cabines individuais com iluminação branca. Foram convidados 6 voluntários não treinados a participar da pesquisa, da comunidade acadêmica da Universidade Regional Integrada do Alto Uruguai e das Missões-URI Campus Erechim, envolvendo estudantes de graduação, professores e funcionários. Os provadores foram solicitados a avaliar o aroma, sabor, acidez, dulsor (suvidade), carbonatação e avaliação geral, classificando cada parâmetro como mau (1), não suficiente (2), aceitável (3), bom (4) e muito bom (5).

Ressalta-se que foram seguidas todas as orientações de monitoramento e prevenção da contaminação causada pelo Covid 19, conforme protocolo estabelecido pela Instituição. O convite foi realizado por meio divulgação oral da análise sensorial na instituição de ensino. Todos os voluntários, responderam a um questionário, para possibilitar a caracterização das mesmas sobre gênero, grau de escolaridade, faixa etária e se tinham o hábito de consumir Kombucha, com a finalidade de identificar a familiaridade destes provadores com o tipo de amostra apresentada.

\section{Resultados e Discussão}

Os resultados referentes a caracterização das amostras de kombucha produzidas a partir de três formulações diferentes, foram avaliados de modo a comparar a evolução durante o processo fermentativo. A Tabela 1 apresenta os valores de $\mathrm{pH}$, densidade, sólidos solúveis e acidez total das formulações de chá de kombucha durante e após a fermentação com diferentes culturas fermentativas. 
Tabela 1. Valores de pH, densidade, sólidos solúveis e acidez total das formulações de chá de kombucha durante e após a fermentação com diferentes culturas fermentativas.

\begin{tabular}{|c|c|c|c|}
\hline Formulações & Inicial & Após 24h & Final da Fermentação \\
\hline \multicolumn{4}{|c|}{$\mathrm{pH}$} \\
\hline $\mathrm{F} 1$ & $6,20 \pm 0,05$ & $4,20 \pm 0,06$ & $3,80 \pm 0,11$ \\
\hline $\mathrm{F} 2$ & $6,20 \pm 0,05$ & $3,60 \pm 0,05$ & $3,60 \pm 0,05$ \\
\hline $\mathrm{F} 3$ & $6,20 \pm 0,05$ & $3,90 \pm 0,05$ & $3,20 \pm 0,05$ \\
\hline \multicolumn{4}{|c|}{ Densidade $\left(\mathrm{kg} / \mathrm{dm}^{3}\right)$} \\
\hline F1 & $1,002 \pm 0,50$ & $1,003 \pm 0,57$ & $1,003 \pm 0,57$ \\
\hline $\mathrm{F} 2$ & $1,002 \pm 0,50$ & $1,010 \pm 0,57$ & $1,004 \pm 0,55$ \\
\hline F3 & $1,002 \pm 0,50$ & $1,015 \pm 0,52$ & $1,011 \pm 0,53$ \\
\hline \multicolumn{4}{|c|}{ Sólidos Solúveis $\left({ }^{\circ}\right.$ Brix) } \\
\hline $\mathrm{F} 1$ & $6,0 \pm 0,05$ & $3,0 \pm 0,05$ & $2,0 \pm 0,06$ \\
\hline $\mathrm{F} 2$ & $6,0 \pm 0,05$ & $3,3 \pm 0,06$ & $1,5 \pm 0,05$ \\
\hline $\mathrm{F} 3$ & $6,0 \pm 0,05$ & $4,4 \pm 0,05$ & $3,2 \pm 0,05$ \\
\hline \multicolumn{4}{|c|}{ Acidez Total (\%) } \\
\hline F1 & $2,5 \pm 0,05$ & $3,5 \pm 0,05$ & $5,0 \pm 0,05$ \\
\hline $\mathrm{F} 2$ & $2,5 \pm 0,05$ & $3,0 \pm 0,05$ & $6,5 \pm 0,05$ \\
\hline F3 & $2,5 \pm 0,05$ & $1,0 \pm 0,05$ & $7,4 \pm 0,05$ \\
\hline
\end{tabular}

F1 - Sacharomyces cerevisiae e cultura mãe; F2 - fermento nativo e a cultura mãe; F3 - apenas cultura mãe. Fonte: Autores.

Comparando os valores de $\mathrm{pH}$ obtidos na Tabela 1, observa-se que em todos os fermentos de origem, o valor diminui ficando dentro do limite estabelecido pela legislação brasileira, que estabelece o valor mínimo de 2,5 e máximo de 4,2 (Brasil, 2019). A diminuição do pH ao final da fermentação se deve ao consumo dos açúcares presentes no meio e o aumento da concentração de ácidos orgânicos, que é característico do metabolismo das bactérias acéticas.

Valores de pH e acidez total são parâmetros padrão que indicam o sucesso do processo de produção (Jayabalan et al., 2014). Malbasa et al. (2011), observaram valores de pH de 2,95 e 3,21 para kombuchas tradicionais com chá preto e com chá verde, respectivamente, após 7 dias de fermentação.

Loncar et al. (2006), observaram que o valor do pH diminui ao longo do tempo em amostras de chá de kombucha que foram fermentadas por 10 dias usando chá preto e açúcar sacarose, e essa diminuição se deve aos ácidos orgânicos resultantes da fermentação. Como resultado da fermentação do chá kombucha realizada por 2 semanas com açúcar de sacarose usando chá preto e chá verde, foi observado que o valor do pH diminuiu rapidamente de 5 para 3 a 3,5 (Kallel et al., 2012). Resultados semelhantes foram obtidos neste estudo. Acreditamos que a cultura mãe tenha em sua proporção um percentual maior de bactérias acéticas desta forma a metabolização em ácidos orgânicos é mais rápida e mais alta que os demais.

A densidade é um importante indicativo da metabolização dos sólidos solúveis contidos no produto, além de ser de fácil execução e evidenciar o consumo de substrato no decorrer do tempo fermentativo. O valor inicial de densidade antes da adição dos diferentes fermentos, foi de 1,020. Levando em consideração os resultados obtidos na Tabela 1, é possível visualizar que em todos os tipos de fermento a densidade diminuiu após o início do processo fermentativo, sendo que a maior taxa de variação foi utilizando o fermento nativo.

A levedura comercial e a levedura nativa tiveram um início de fermentação mais intenso quando comparado a cultura mãe, observado pelo consumo de açúcares após 24h (Tabela 1).

O teor de sólidos solúveis em água inicial do chá antes da adição dos fermentos foi de 6,0. Os valores foram significativamente diferentes no início da fermentação e depois em todas as variedades de fermento. A levedura industrial (Saccharomyces cerevisiae) consumiu a metade dos açúcares após $24 \mathrm{~h}$ de fermentação. A maior taxa de redução do teor de 
sólidos solúveis ocorreu na fermentação com levedura nativa + cultura mãe. Já, na fermentação apenas com a cultura mãe a redução foi mais lenta, mantendo um maior teor de sólidos solúveis após a fermentação ( $3,2{ }^{\circ}$ Brix). Estudos relatam que a quantidade de sacarose diminui linearmente nos primeiros 30 dias desde o início da fermentação e, a seguir, apresenta uma diminuição lenta (Chen e Liu, 2000).

Ao final da fermentação os valores de açúcares redutores totais foram de 4,36, 2,12 e 3,39 g/L para a kombucha fermentada com levedura industrial (S. cerevisiae), levedura nativa com cultura mãe, e somente cultura mãe, respectivamente.

O teor de açúcares totais corresponde ao somatório dos açúcares redutores com os açúcares não-redutores. O conteúdo de açúcares redutores é resultante da hidrólise dos açúcares não-redutores pela ação das leveduras e bactérias acéticas presentes no SCOBY (Santos et al., 2018).

No começo, após $24 \mathrm{~h}$ de fermentação, a levedura industrial se sobressaiu em comparação aos demais fermentos. O fermento de levedura nativa e cultura mãe não obteve uma melhor acidez, pois metabolizou mais rápido as bactérias e leveduras presentes. A cultura mãe, não se desenvolveu no patamar esperado, quando comparado a levedura (Tabela 5).

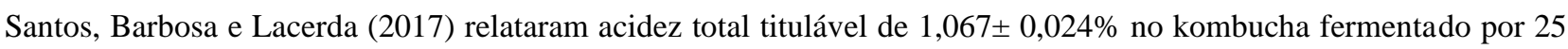
dias, e Santos et al. (2019) encontraram os valores de 0,27 para a bebida dia 0 e 1,89 no dia 6 . Ambos os estudos apresentaram valores inferiores aos descritos neste trabalho.

Os resultados apresentados na Tabela 2 demostram que o teor alcoólico alcançado na bebida, condiz com o que se espera de uma cultura mista.

Tabela 2. Teor alcoólico das formulações de chá de kombucha após a fermentação com diferentes culturas fermentativas.

\begin{tabular}{cc}
\hline Formulações & Teor Alcoólico (\%) \\
\hline F1 & 2,5 \\
F2 & 2,0 \\
F3 & 1,0 \\
\hline
\end{tabular}

F1 - Sacharomyces cerevisiae e cultura mãe; F2 fermento nativo e a cultura mãe; F3 - apenas cultura mãe. Fonte: Autores.

A faixa de etanol verificada neste estudo mostrou uma variação de 1,0 a 2,5\% (v/v), ficando acima do limite permitido pela legislação do Brasil de 0,5\% (v/v) para bebidas não alcoólicas (Brasil, 2019). De maneira semelhante, valores de etanol na faixa de $1,12-2,00 \%(v / v)$ foram encontrados em um estudo envolvendo 18 kombuchas comercialmente disponíveis no mercado dos EUA (Talebi et al., 2017).

Na produção de kombucha, assim como em todos os alimentos e bebidas fermentados, também ocorre a formação de etanol. Porém, como a produção da bebida ocorre em um ambiente com presença de oxigênio, a maior parte do etanol é oxidado por bactérias em ácido acético (May et al., 2019). A concentração de etanol determinada nas diferentes marcas de kombucha difere devido a diferentes procedimentos de fabricação incluindo a concentração do chá e do açúcar, insumos utilizados na saborização, parâmetros da fermentação e composição microbiológica do SCOBY (Reva et al., 2015; Talebi et al., 2017). Além disso, as condições de armazenamento também podem influenciar na evolução do grau alcoólico do produto engarrafado (Talebi et al., 2017).

A análise sensorial foi realizada nas Kombuchas com tratamento térmico de pasteurização (A) e sem tratamento térmico (B), sendo calculada a média de cada atributo avaliado. Comparando-se as kombuchas pasteurizada e não pasteurizada obtidas por fermentação com levedura industrial e cultura mãe (Figura 3), pode-se observar uma diferença de percepção entre a pasteurizada e a natural. A bebida natural apresentou uma carbonatação mais evidente e um equilíbrio interessante, porem a bebida pasteurizada teve melhor pontuação na percepção de aroma, sabor, dulçor e acidez. 
Figura 3. Análise sensorial de kombucha fermentada com levedura industrial e cultura mãe (F1), sem pasteurização (A) e com pasteurização (B).
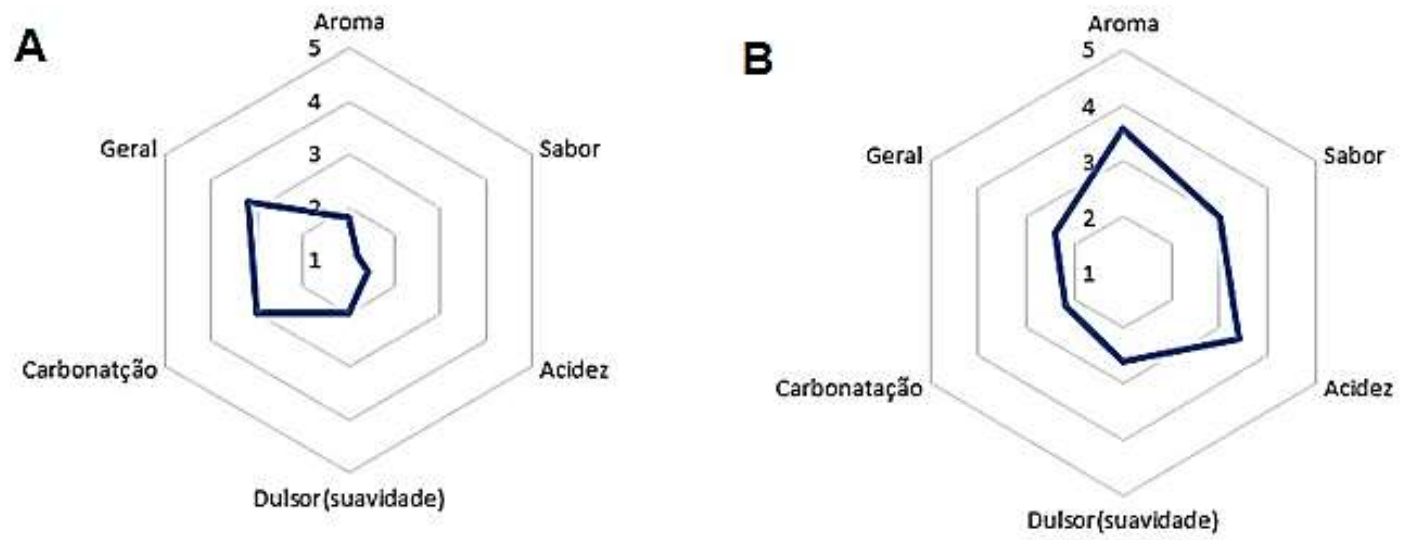

Fonte: Autores.

A kombucha fermentada com levedura nativa e cultura mãe não pasteurizada teve uma aceitação melhor que a kombucha pasteurizada (Figura 4). Neste caso, a pasteurização prejudicou quase todos os elementos de constituição, com exceção do aroma que obteve a mesma pontuação.

Figura 4. Análise sensorial de kombucha fermentada com levedura nativa e cultura mãe (F2), sem pasteurização (A) e com pasteurização (B).
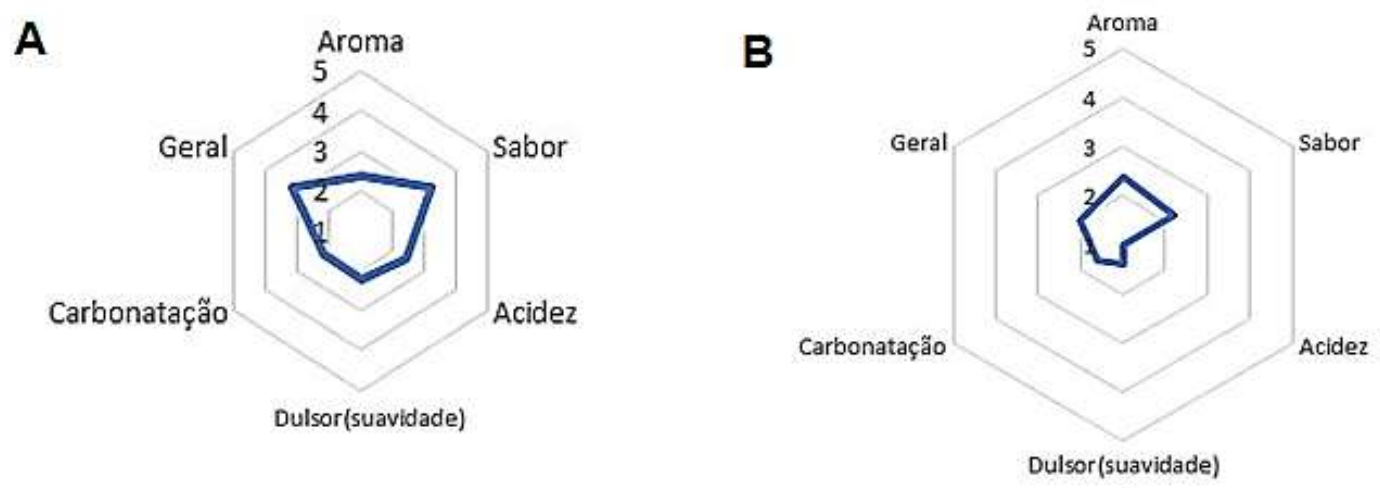

Fonte: Autores.

A Kombucha obtida com a cultura mãe não pasteurizada (A) apresentou uma aceitação maior em todos os atributos, quando comparada com a kombucha pasteurizada (B) obtida pela mesma fermentação (Figura 5). 
Figura 5. Análise sensorial de kombucha fermentada somente com cultura mãe (F3), sem pasteurização (A) e com pasteurização (B).
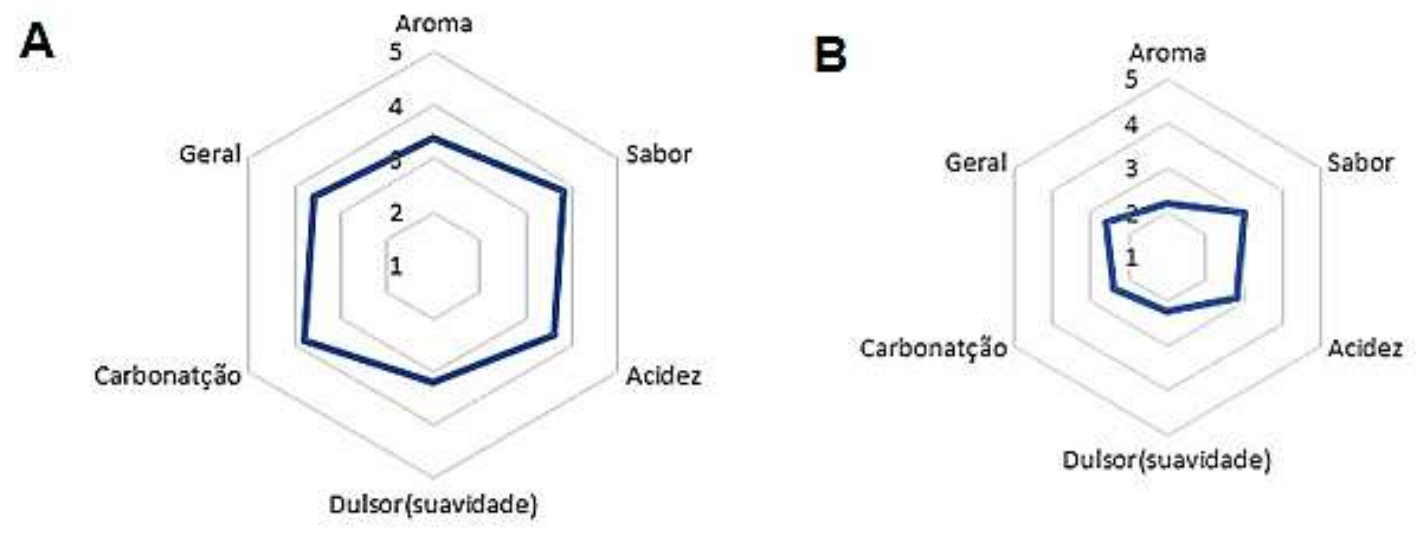

Fonte: Autores.

Comparando-se as três fermentações, observa-se que a kombucha fermentada apenas com a cultura mãe, sem pasteurização apresentou uma maior aceitação em todos os atributos avaliados, comparando-se com as demais formulações e tratamentos térmicos.

\section{Conclusão}

As diferentes culturas aplicadas à mesma formulação de kombucha resultaram em produtos diferenciados, tanto do ponto de vista físico-químico quanto do ponto de vista sensorial. Tanto a cultura com levedura industrial como a com levedura nativa tiveram uma metabolização maior dos açúcares com uma menor acidez final e maior formação de álcool. A velocidade de conversão dos açucares em álcool dos dois preparados com fermentação com leveduras foram maiores que a formulação com somente cultura mãe. Já a cultura mãe produziu uma quantidade maior e ácidos orgânicos em detrimento a conversão dos açúcares do mel em álcool. Também sobraram mais açucares residuais (não fermentados) o que levou a um equilíbrio interessante entre acidez e dulçor. Esta complexidade levou a uma tendência de maior aceitabilidade no critério sensorial.

Levando em consideração o apelo funcional da Kombucha, faz-se necessário as avaliações das propriedades bioativas dos produtos elaborados, além de testar novas formulações para abranger um maior número de consumidores e tornar este produto mais atrativo frente aos existentes no mercado.

\section{Referências}

Amarasinghe, H., Weerakkody, N. S. \& Waisundara, V. Y. (2018) Evaluation of physicochemical properties and antioxidant activities of kombucha "Tea Fungus" during extended periods of fermentation. Food Science \& Nutrition, 6(3), 659-665.

Battikh, H., Bakhrouf, A. \& Ammar, E. (2012) Antimicrobial effect of Kombucha analogues. LWT - Food Science and Technology, 47, 71-77.

Brasil. Instrução Normativa n 41, de 17 de setembro de 2019. Padrão de Identidade e Qualidade da Kombucha.

Chen, C. \& Liu, B. (2000) Changes in major components of tea fungus metabolites during prolonged fermentation. Journal of Applied Microbiology, 89 (5), 834-839.

Cardoso, R. R., Oliveira, R., F. O., Santos D'almeida, C. T., Nascimento, T. P., Pressete, C. G., Azevedo, L., Martino, H. S. D., Cameron, L. C., Ferreira, M. S. L. \& Barros, F. A. R. (2020) Kombuchas from green and black teas have different phenolic profile, which impacts their antioxidant capacities, antibacterial and antiproliferative activities. Food Research International, 128, 108782.

Dufresne, C. \& Farnworth, E. (2000) Tea, Kombucha, and health: a review. Food Research International. 33, 409-421.

Gamboa-Gomez, C. I., Simental-Mendia, L. E., Gonzalez-Laredo, R. F., Alcantar-Orozco, E. J., Monserrat-Juarez \& V. H., Ramirez-España, J. C. (2017) In vitro and in vivo assessment of anti-hyperglycemic and antioxidant effects of Oak leaves (Quercus convallata and Quercus arizonica) infusions and fermented beverages. Food Research International, 102, 690 - 699. 
Greenwalt, C. J., Steinkraus, K. H. \& Ledford, R. A. (2000) Kombucha, the Fermented Tea: Microbiology, Composition, and Claimed Health Effects. Journal of Food Protection, 63, $976-981$.

Hill, D., Sugrue, I., Arendt, E., Hill, C., Stanton, C. \& Ross, R. P. (2017) Recent advances in microbial fermentation for dairy and health. F1000 Research, 6, 751.

IAL - Instituto Adolfo Lutz. Normas Analíticas do Instituto Adolfo Lutz. v. 1: Métodos químicos e físicos para análise de alimentos. $4^{\mathrm{a}}$ ed. São Paulo, 2009.

Jayabalan, R., Malbaša, R.V., Lončar, E. S., Vitas, J. S. \& Sathishkumar, M. (2014) A review on kombucha tea-Microbiology, composition, fermentation, beneficial effects, toxicity, and tea fungus. Comprehensive Reviews in Food Science and Food Safety, 1, 538-550.

Jayabalan R., Malini K., Sathishkumar M., Swaminathan K. \& Yun S.-E. (2010) Biochemical Characteristics of Tea Fungus Produced During Kombucha Fermentation. Food Science and Biotechnology, 19 (3), 843-847.

Jayabalan R., SubathradevI P., Marimuthu S., Sathishkumar M. \& Swaminathan K. (2008) Changes in free-radical scavenging ability of kombucha tea during fermentation. Food Chemistry, 109 (1), 227-234.

Jayabalan R., Marimuthu S. \& Swaminathan K. (2007) Changes in content of organic acids and tea polyphenols during kombucha tea fermentation. Food Chemistry, 102(1), 392-398.

Kallel, L., Desseaux, V., Hamdi, M., Stocker, P. \& Ajandouz, E.H. (2012) Insights into the fermentation biochemistry of Kombucha teas and potential impacts of Kombucha drinking on starch digestion. Food Research International. 49 (1), 226-232.

Kaur, N. \& Singh, P. D. (2017) Deciphering the consumer behaviour facets of functional foods: A literature review. Appetite, 112, $167-187$.

Köche, J. C. (2011) Fundamentos de metodologia científica: teoria da ciência e iniciação à pesquisa. Vozes.

Lobo, R. O., Sagar, B. K. C. \& Shenoy, C. K. (2017) Bio-tea previne a desestabilização da membrana durante lesão miocárdica induzida por isoproterenol. Journal of Microscopy and Ultrastructure, 5, 146-154.

Loncar, E., Djuric, M., Malbasa, R., Kolarov, L. \& Klasnja, M. (2006) Influence of Working Conditions Upon Kombucha Conducted Fermentation of Black Tea. Food and Bioproducts Processing, 84(3), 186-192.

Malbasa, R., Vitas, J., Loncar, E., Grahovac, J. \& Milanovic, C. (2014) Optimisation of the antioxidant activity of kombucha fermented milk products.. Checa Journal of Food Sciences, 32, 477-484.

Malbasa, R., Loncar, E., Vitas, J. \& Canadanović-Brunet, J. (2011) Influence of starter cultures on the antioxidant activity of kombucha beverage. Food Chemistry, 127, 1727-1731.

Malbasa, R., Loncar, E. \& Djuric, M. (2008) Comparison of the products of Kombucha fermentation on sucrose and molasses. Food Chemistry, 106, 10391045 .

May, A., Narayanan, S, Alcock, J., Varsani, A., Maley, C. \& Aktipis, A. (2019) Kombucha: a novel model system for cooperation and conflict in a complex multi-species microbial ecosystem. PeerJ, e7565.

Nguyen, N. K., Dong, N. T. N., Nguyen, H. T. \& Le, P. H. (2015) Lactic acid bacteria: promising supplements for enhancing the biological activities of kombucha. SpringerPlus, 4, 91.

Pereira A. S., Pereira, A. S., Shitsuka, D. M., Parreira, F. J., Shitsuka, R. (2018) Metodologia da pesquisa científica. UFSM.

Reva, O. N., Zets, I. E., Ovcharenko, L. P., Kukharenko, O. E., Shpvlova, S. P, Podolich, O. V., vera, J. P. \& Kozvorovska, N. O. (2015) Metabarcoding of the kombucha microbial community grown in different microenvironments. AMB Express, 5(1), 214.

Roos, J. \& Vuyst, L. (2018) Acetic acid bacteria in fermented foods and beverages. Current Opinion in Biotechnology, 49, 115-119.

Santos, M. J. (2016) Kombucha: Caracterização da Microbiota e Desenvolvimento de Kombucha: Caracterização da Microbiota e Desenvolvimento de Novos Produtos Alimentares Para Uso em Restauração. 119 f. Dissertação (Mestrado) - Instituto Superior de Agronomia, Universidade de Lisboa.

Santos, Y. M. A, Mota, M. M. A., Santiago, A. M., Gouveia, D. S., Dantas, R. L. \& Moreira, I. S. (2019) Avaliação da composição de kombucha a base de diferentes chás (verde e preto). Revista Brasileira de Gestão Ambiental, 12, 1-6.

Santos, Y. M. A., Araújo, F. E. M. O., Mota, M. M. A., Gouveia, D. S., Silva, M. J. S. \& Moreira, I. S. (2018) Avaliação da composição de kombucha a base de diferentes chás (hibisco e verde). IV Encontro Nacional da Agroindústria. 6.

Santos, W. C. R., Barbosa, C. D. \& Lacerda, I. A. C. (2017) Obtenção e caracterização de kombucha de chá preto. $69^{\circ}$ Reunião Anual da Sociedade Brasileira para o Progresso da Ciência (SBPC)- UFMG. Belo Horizonte/MG.

Sarkava, P., Akan, E. \& Kinik, O. (2020) Use of kombucha culture in the production of fermented dairy beverages. LWT- Food Science and Technology. 110326,3 .

Schmitt, E., Galli, F., Menozzi, D., Maye, D., Touzard, J. M., Marescotti, A., Six, J. \& BrunorI, G. (2017) Comparing the sustainability of local and global food products in Europe. Journal of Cleaner Production, 165, 346-359.

Selhub, E. M., Logan, A. C. \& Bested, A. C. (2014) Fermented foods, microbiota, and mental health: ancient practice meets nutritional psychiatry. Journal of Physiological Anthropology, 33 (2), 1180- 6805. 
Research, Society and Development, v. 10, n. 16, e106101622384, 2021

(CC BY 4.0) | ISSN 2525-3409 | DOI: http://dx.doi.org/10.33448/rsd-v10i16.22384

Sknepnek, A., Pantic, M., Matijasevic, D., Miletic, D., Levic, S., Nedovic, V. \& Niksic, M. (2018) Novel Kombucha Beverage from Lingzhi or Reishi Medicinal Mushroom, Ganoderma lucidum, with Antibacterial and Antioxidant Effects, Int J Med Mushrooms, 20, 243-258.

Srihari, T. \& Satyanarayana, U. (2012) Changes in Free Radical Scavenging Activity of Kombucha during Fermentation. Journal of Pharmaceutical Sciences and Research, 4 (11), 1978-1981.

Talebi, M., Frink, L. A., Patil, R. A. \& Armstrong, D. W. (2017) Examination of the Varied and Changing Ethanol Content of Commercial Kombucha Products. Food Analytical Methods, 10, 12, 4062-4067.

Vijayaraghavan, R., Singh, M., Rao, P., Bhattacharya, R., Kumar, P., Sugendran, K. \& Singh, R. (2000) Estudos de toxicidade oral subaguda (90 dias) do chá de Kombucha. Ciências Biomédicas e Ambientais. 13, 293-299.

Villarreal-Soto, S. A., Beaufort, S., Bouajila, J., Souchard, J. P. \& Taillandier, P. (2018) Understanding Kombucha Tea Fermentation: A Review. Journal of Food Science, 83, 580-588.

Vitas, J. S., Malbasa, R. V., Grahovac, J. A. \& Loncar, E. S., (2019) A atividade antioxidante de produtos lácteos fermentados de kombucha com urtiga e salgados de inverno. Indústria Química e Engenharia Química Trimestral. 19, 129-139.

Watawana, M. I., Jayawardena, N., Gunawardhana, C. B. \& Waisundara, V. Y. (2015) Health, Wellness, and Safety Aspects of the Consumption of Kombucha. Journal of Chemistry, 2015, 1-11. 